\title{
eSGarden: a European initiative to incorporate ICT in schools
}

\author{
Sara Blanc ${ }^{1}$, José V. Benlloch-Dualde ${ }^{2}$ \\ ${ }^{1,2}$ Computer Engineering Dept., Universitat Politècnica de València, Valencia, Spain.
}

\begin{abstract}
Knowledge transfer to the society is undoubtedly one of the main objectives of Universities. However, it is important that these advances reach the youngest, many of them, future university students. Having this in mind, a European project around how incorporating ICT in school gardens was proposed (SCHOOL GARDENS FOR FUTURE CITIZENS, 2018-1-ESO1KA201-050599). In this project, both universities and schools, belonging to five European countries, are collaborating with public and private organizations with social concerns, environmental responsibility and sustainability.
\end{abstract}

School gardens is a broad topic that combine technological needs for managing and control with education in values of environmental sustainability, social inclusion and citizenship, transmission of tradition, and the promotion of digital culture in both girls and boys from the early school stages. These last aspects are aligned with some sustainable development targets (SDGs), such as ensuring healthy lives and promote well-being for all at all ages, inclusive and equitable quality education, gender equality or responsible consumption.

A further challenge of the consortium is to extend the proposed approach to other schools throughout Europe with the same interests and impact, considering cultural diversity and climate differences.

Keywords: School gardens; sustainable development goals; digital competences; inclusive education. 


\section{Introduction}

The defence of school gardens and its advantages in education is not new. For example, the network Eco-Schools (https://www.ecoschools.global/) groups 51.000 schools of 67 countries. They define themselves as the largest global sustainable schools programme - it starts in the classroom and expands to the community by engaging the next generation in action-based learning. In the last years, different projects have been funded from the European Union within the framework of the Erasmus+ program. For instance, "Erasmus Gardening: Culture and Science" (https://erasmusgardening.poli.hu/) or "gARDENS to gROW: Urban Horticulture for Innovative and Inclusive Early Childhood Education" http://www.distal.unibo.it/it/ricerca/progetti-di-ricerca/attivi/gardens-to-grow-urban-

horticulture-for-innovative-and-inclusive-early-childhood-education), the last one still in progress until 2020.

All the former initiatives highlight school gardens as a learning vehicle that help students to reach many different goals. A holistic learning approach encourages knowledge of social, economic and cultural understanding of the regions in which students live. Moreover, it will promote both specific and soft competencies, and prepare students for a global world in continuous change. Adding the ecological approach, schools' gardens also promotes values for future citizenship towards respect for the environment and responsible behaviour, sustainable production of food or healthy nutrition. For example, FAO, in its document "A NEW deal FOR school gardens " (Food and Agriculture Organization, 2010) promotes the use of school gardens as well as the application of Garden Based Learning (GBL) methodology (Desmond, Grieshop \& Subramaniam, 2004).

General speaking, school gardens deal with many Sustainable Development Goals (United Nations, 2015) such as "ensure healthy lives and promote well-being for all at all ages" (SDG 3); "ensure inclusive and equitable quality education and promote lifelong learning opportunities for all (SDG 4); "achieve gender equality and empower all women and girls (SDG 5); or "ensure sustainable consumption and production patterns" (SDG 12). Hence, school gardens offer a big opportunity to invite students to look ahead and contribute in the world transformation, according to the 2030 Agenda for Sustainable Development.

Technology is well received by the new digital generations and the ICT affordances are undoubtedly very valuable. However, the introduction of technology is not always tackled in the proper way. There is a consensus in the research available that the primary factor that influences the effectiveness of learning is not the availability of technology, but the pedagogical design for effective use of ICT (BECTA, 2004; Wang \& Woo, 2007). Therefore, provided that pedagogical approaches are considered, ICT can be incorporated in formats better accepted by all students as a means of observing the reality, sharing 
knowledge, stimulating creativity, stoking the initiative and empowering students in their own learning.

eSGarden (School Gardens for Future Citizens) is a project (2018-2021) funded by the Erasmus+ programme under the KA2: Cooperation for innovation and exchange of good practices (https://ec.europa.eu/programmes/erasmus-plus/projects/eplus-projectdetails/\#project/2018-1-ES01-KA201-050599; https://esgarden.blogs.upv.es/). This project proposes an innovative technology transferring pilot which pretends to bring the garden to the classroom activities through the creation of a virtual environment. The purpose is to transform garden observation and work in data and information which allow teachers on the one hand, to build their own educational resources and, on the other hand, to establish a connection between the physical world (garden) and the digital one (virtual), linking informal activities outside the classroom with the content of the curricula. It eases the integral development of the students, helping to improve their self-esteem and personal satisfaction because the activities carried out are highly motivating and link the process of learning with the development of both personal and academic skills. Moreover, school gardens improve the relationship between the community and the school, since social and educative networks are created, fostering the feeling of belonging to a bigger community.

\section{Project partners}

The project partnership is integrated by primary and secondary schools, universities, a nonprofit organization and a small agro-technology company. Among schools, Spain, Portugal, Slovenia and Greece are represented. Among non-school partners, there are three universities: Universitat Politècnica de València (UPV), in Spain; Universidade do Porto (UP), in Portugal; and Universitatea Technicà Cluj-Napoca (UTCN), in Romania. Moreover, the consortium incorporates Fundación CajaMar, a Spanish non-profit organization, and a small company, TBAgroSensors S.L., located in Valencia, Spain.

La Purisima Franciscanas school, in Valencia, will provide knowledge and advice about the definition of good practices in building the school curriculum around gardens. It will lead the methodological approach and the schools coordination. This school together with Smartno pod Smarno Goro Primary school, in Ljubljana, Slovenia; Agrupamento de Escolas de Paredes, in Porto, Portugal, and the $4^{\text {th }}$ of Primary School, in Preveza, Greece, serve as tester and will get quality feedback about the design of school gardens activities and educational resources created starting from collected gardens data. Schools are a fundamental part in the development of this new methodological approach, its quality evaluation and the resources production to support future project sustainability.

Preveza, in Greece, participates through the Directorate of Primary School Education. This organization is responsible for 38 general education nursery schools and 31 general primary 
education schools. It employs approximately 537 teachers and about 4090 students are currently enrolled in its schools. Its role is to coordinate, supplement, support and implement the educational policies of the Ministry, coordinate and guide the work of schools and lead inniciatives. It will coordinate the project, activities and testing, within a suitable group of students' participants from Preveza.

$U P$ is involved into the project through the OBVIE department for advisoring on how teachers' activities around the school garden can be pedagogically adequate, in order to increase quality of the materials and their impact on students' learning. It is relevant to point out that an especial focus will be placed on low achievers and families with low incomes and disadvantaged social backgrounds. OBVIE will lead the supervision and evaluation about the establishment of necessary principles, targets and approaches to ensure the objectives of development and global citizen education. The Centre for Development Cooperation at the UPV will collaborate in the task with the advisored supervision of associated partners.

Fundación CajaMar is focused on supporting teacher and administrative staff in schools with training activities around agricole uses and its adaptation to school gardens and healthy nutrition, as well as its impulse through school gardens. It leads the screenplay book on school gardens in both paper book short edition and free access electronic format.

$U P V$ is responsible for the project coordination, management and dissemination. It leads research and development of ICT tools and materials. This task requires of developing the virtual garden and activities around this topic. The UPV will provide schools, teachers and schoolchildren with ICT transferable knowledge to the. In particular, it will offer elearning know-how that present success cases with potential adoption by schools and help them to develop ICT resources. It also will provide expertise about crops, tillage and irrigation culture from former studies. Finally, cooperation with the Senior University (http://www.upv.es/entidades/AUS/index-en.html), will help to increase synergies and links with culture in a circular knowledge.

UTCN will contribute in the research and development of ICT tools and materials as well as in supporting teachers training to adopt the new digital paradigm, according to the European Framework for the Digital Competence of Educators (Redecker, 2017).

TBAgrosensors will develop open-source resources to adapt comercial agro-field instruments, such as soil-moisture probes, water counters and electrovalves, to the programme within technology activities oriented to children and youngs to work by themselves on the configuration and deployment of small-electronics equipment to control their school gardens. 
All partners will be involved in disseminating project results both locally, through actions such as workshops or presentations, and internationally, through papers in journals and international conferences.

\section{Objectives}

On a pilot experience it is possible to define targets, to observe deficiencies on needs and to create a suitable and adapted ICT environmentaccepted by students, teachers and in general, throughout the educational community.

The school gardens combine technological needs for managing and control with education in values. In particular, themes than can be addressed are: environmental sustainability, social inclusion and citizenship, transmission of tradition and the promotion of digital culture in both girls and boys from the early school stages, as shown in Fig. 1.

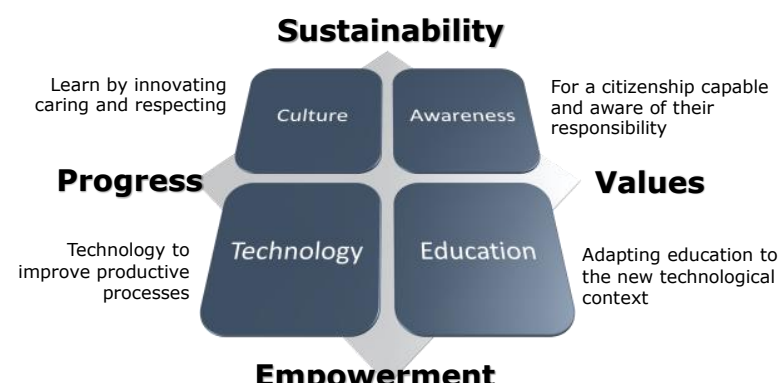

Figure 1. A project with four axes.

It is a challenge to carry out this integration so that it can be extended to other schools throughout Europe, provided they have the same interests and, of course, taking into account cultural diversity and climate differences.

In summary, the project mission is to work on good practices, tools and resources which help to a broad community to create and produce adapted educational resources to their own needs to improve students' specific and soft skills, language skills and social education.

\subsection{Specific objectives in social learning}

The project focuses on developing knowledge in digital project-based learning around an inclusive programme which promotes equality of opportunities by giving an individual education, fosters students' implication, solidarity and cooperation. 
Thus, it is essential to design a learning methodology based on the adoption of school gardens in the school's curriculum within an ICT approach. During the project, research on school gardens project-based methodology will be implemented and tested in the schools' partners defining good practices and activities. The methodology will be implemented as a programme to primary curriculum in a transversal design on different topics such as environment, society, economy, nutrition, among others. Relevant improvements will be focused on linguistic, technological, cultural and social skills.

\subsection{Specific objectives in digital based learning}

As a case study, the project connects gardening and technology under a learning-by-doing project. Non-school partners will contribute on developing ICT tools and resources to promote children virtual interaction with the school garden. It is considered useful to save data about garden activities that can enable to work on skills such as deduction, critical thinking or collaborative learning throught gamification. Moreover, diversity is contemplated through the adaptation of interfaces for children with special needs.

\subsection{Specific objectives in circular community knowdlege}

The third objective is to transform school gardens into circular knowledge breaking down frontiers in a global expansion throughout a diverse community. In this line, the project contributes with both activities and output resources.

Activities such as selling markets, will connect the school with the surrounding community. To accomplish that, these activities are carried out with the collaboration of seniors, families and neighbours, to promote the immersion of learning in the community. The culture and agro-knowledge transfer is the base stone of this objective which focuses on local traditions and respect.

Moreover, the project works on tangible intellectual outputs to help schools to adopt the methodology.

\subsection{Specific objectives in learning-by-doing}

lmprove quality, motivation and students' achievement through a more attractive holistic real-life based programme close to children and, in turn, innovative, where they can propose ideas, make decisions and acquire responsabilities. "Thinking out of the box" is the life-motive that connects gardens + technology + progress in an equation which results in innovation, creative stimulation and responsibility.

\section{Working Plan}

The principles of eSGarden are: 
- To produce knowledge transfer from University and non-school partners that serves in the improvement of school practices and activities.

- To gain feedback of school necessities and curricula gaps to promote students' learning in current technology advances and social awareness.

- To stimulate the adoption and integration in the schools curricula of new competencies that stimulate talent around the project topic.

Taking these principles into account, the working plan is distributed in three main Work Packages (Fig. 2):

1) WP1: Define a suitable consortium which embrace the expected knowledge in Education, SDGs and Social Learning, ICT Systems, Scholar Programmes and Development, Agro-Food knowledge and Quality Audit.

Project start-up focuses on defining goals, challenges and limits in the schools curricula adaptation. Actions such as internal conferences, face-to-face meetings, evaluation questionnaires or a school teachers intensive training are arranged tools to approximate the interests of each school to the possibilities of knowledge transfer. As each participating school belongs to a different country, they have also diverse legislative frameworks. Therefore, it is necessary to adapt project outputs to each context.

2) WP2: The second work package is set around defining eSGarden contributions in four axis: Education and Social Approach, Education Strategy, Students and Community Interaction and Quality Measurement.

This work package requires the definition of a methological approach to set the educational competences that could lead the change. The strategy will be spread on daily classroom work where proposals will be deployed and observed to distill good practices than can be portable and adaptable to other school contexts.

3) WP3: Finally, the third work package defines the observation throughout Key Indicators useful to measure the qualitative competencial improvement on students, teachers and the community.

eSGarden has defined a set of tangible outputs to multiply the impact of the change to be transformational, innovative, useful and measurable. These project outputs will be ready at the end, in may 2021. 


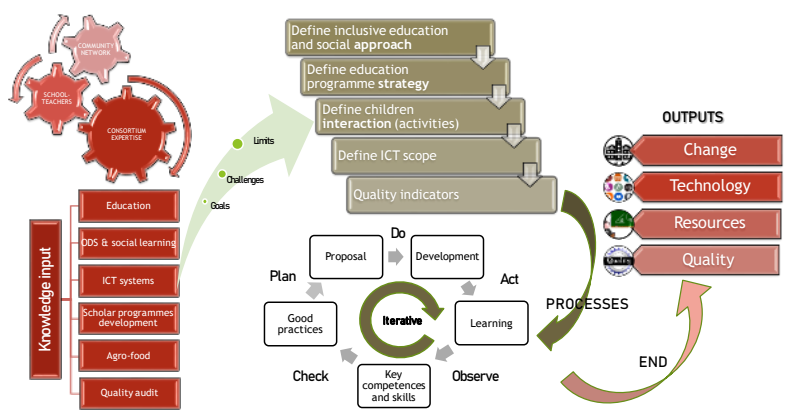

Figure 2. Working plan view.

Fig. 3 shows a schedule of eSGarden milestones. M1 to M5 represent the transnational meetings which will be held during the project in each of the five countries represented in the project: Spain, Portugal, Slovenia, Greece and Romania.

Among the activities included in WP1, schools have to introduce the project to their community with activities around European awareness, such as designing a logo or building new spaces for gardening. Moreover, the team of teachers involved in the project must get recognition in the institutions to facilitate authority to drive future changes.

WP2 includes activities around aspects directly or indirectly linked with gardening and the technology as vehicle. Furthermore, the project is also focused on nutrition, personal development as learners or digital empowerment.

Finally, WP3 includes conferences, papers and workshops where the project outcomes be disseminated.

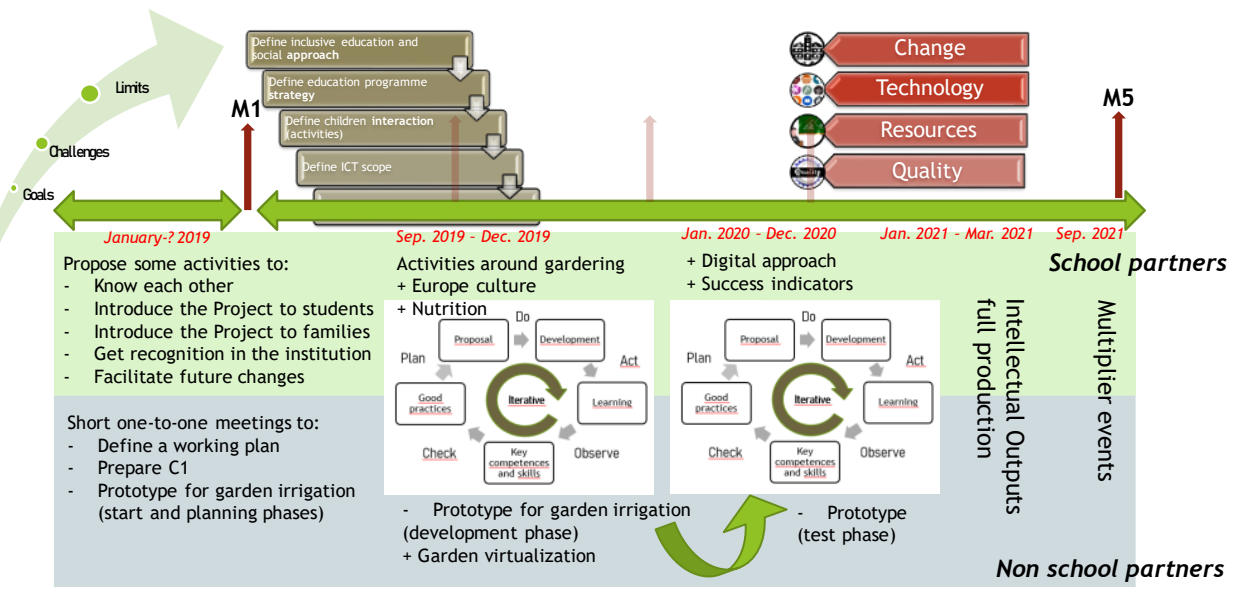

Figure 3. Project route map. 


\section{Conclusions}

This paper presents an in progress knowledge transfer project around how incorporating ICT in school gardens. This broad topic has the advantage of combining technological needs for managing and control, together with education in values, as it addresses themes such as environmental sustainability, social inclusion and citizenship, transmission of tradition and the promotion of digital culture in both girls and boys, from the early school stages. Many of these aspects are aligned with some SDGs, according to the 2030 Agenda for Sustainable Development.

A further challenge of the consortium is to extend the proposed approach to other schools throughout Europe with the same interests and impact, considering cultural diversity and climate differences.

\section{Acknowledgment}

This project is funded by Erasmus+ KA2 Supporting Innovation Action (project number: 2018-1-ES01-KA201-050599 and SEPIE Spanish Service for the Internationalization of Education (2018): http://sepie.es/

\section{References}

BECTA (the British Educational Communications and Technology Agency) (2004). A review of the research literature relating to ICT and attainment. Retrieved July 1, 2019 from https://www.researchgate.net/publication/265003809_ICT_and_Attainment_A_Review _of_the_Research_Literature

Desmond, D., Grieshop, J., \& Subramaniam, A. (2004). Revisiting garden-based learning in basic education. FAO and UNESCO-IIEP. Retrieved July 1, 2019, from http://www.fao.org/3/a-aj462e.pdf

Food and Agriculture Organization of the United Nations (FAO). 2010. A new deal for school gardens. Retrieved July 1, 2019 from http://www.fao.org/3/i1689e/i1689e00.pdf

Redecker, C. (2017). European Framework for the Digital Competence of Educators: DigCompEdu. Punie, Y. (ed). EUR 28775 EN. Publications Office of the European Union, Luxembourg. doi: 10.2760/159770

United Nations. (2015). Transforming our world: the 2030 Agenda for Sustainable Development. $\quad$ Retrieved July $\quad 1, \quad 2019$ from https://www.un.org/ga/search/view_doc.asp?symbol=A/RES/70/1\&Lang=E

Wang, Q. \& Woo, H. L. (2007). Systematic planning for ICT integration in topic learning. Educational Technology and Society, 10 (1), 148-156. 